\title{
Budget plans hint at lean times ahead for Japanese research
}

\section{TOKYO}

Next year promises to be another tight one for Japan's finances, and for the first time in years, basic research may feel the pinch too.

Last week saw government departments submit their initial budget requests for 2006 . As for 2005, the Ministry of Finance is seeking to cut $1.5 \%$ from the overall budget - but this time it has suggested that research funding will have to play its part in the cutbacks.

Japan needs to reduce overall government spending because of its huge national debt, which at $¥ 900$ trillion (US $\$ 8.2$ trillion) amounts to $170 \%$ of its gross domestic product. But the government had so far exempted the research budget from cost-cutting, in an effort to boost global competitiveness.

Research, including the main grant system, accounts for a third of Japan’ $¥ 3.6$ trillion science and technology budget. Although this budget has been declining gently for the past five years, money for research projects has been growing steadily since 1989 . But this year "the overall budget has become tighter", says Tsuyoshi Maruyama, head of the Science and Technology Policy Bureau at the education ministry, and the finance ministry has suggested a cut of 2-3\% to the research budget.

To cope with such constraints, the government wants to prioritize how money allocated for research is spent. It plans to focus on largescale projects such as space missions and supercomputers, which have lost out in recent years to areas such as nanotechnology and life sciences.

Among the big-ticket projects on the educa-

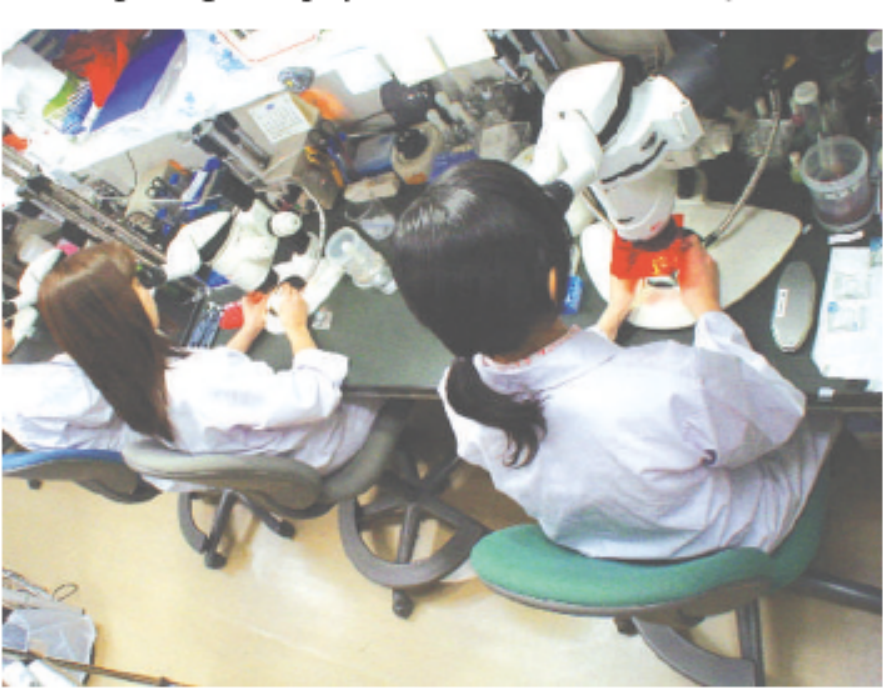

tion ministry's shopping list for funds is the Global Earth Observation System of Systems. This ten-year international project will create a unified Earth observation system (see Nature 433,$789 ; 2005$ ), and the ministry is seeking $¥ 27.6$ billion for Japan’s contribution to it next year. Other areas that would benefit under the budget request include the development of advanced proteomics analysis technologies and RNA research.

But many scientists are worried that this new focus on big projects will absorb the lion's share of the money, meaning cuts for other areas. One senior official at the education ministry says he fears that cash for life sciences overall could be cut by about $¥ 13.5$ billion. All of that would come from research projects, he adds, as it is difficult to reduce personnel costs. Yoshiki Hotta, a biologist and head of the Research Organization of Information and Systems, says he understands the need to streamline costs. But he adds that he is disappointed that the tighter budget meant the education ministry didn't pass on many of his organization's research proposals to the finance ministry. "Even though we want to present new ideas, we can't," Hotta says. "That will discourage researchers and dampen Japan's science."

The final decision on the research budget won't be taken until December, and the finance ministry may yet prove to be flexible. It could, for example, allocate science a slice of a $¥ 100$ billion special budget that the government will set aside to finance important policies. Ichiko Fuyuno

\section{Scaling down:} researchers in Japan may have to tighten their belts nextyear.

\section{Chernobyl: poverty and stress pose 'bigger threat' than radiation}

The Chernobyl nudear accident in 1986 will lead to far fewer deaths than originally thought, according to a report from the United Nations.

Some 4,000 people — including emergency workers and residents of the most contaminated areas - could eventuallydie of factors linked to radiation exposure, the report says. Earlier estimates had ranged widely but regularly suggested that there could be many tens of thousands of deaths (see Nature 351,$4 ; 1991$ ).

"The effects on public health were not nearly as substantial as had at first been feared," says Michael Repacholi, head of the radiation programme at the World Health Organization in Geneva.

Repacholi was among more than $\mathbf{1 0 0}$ scientists, economists and health experts who worked on the 600 -page document, which aimed to summarize the available scientific data on the accident and the countries most affected by it: the Ukraine, Belarus and Russia. The report was due to be released by the Chernobyl Forum at a meeting in Vienna this week.

On 26 April 1986, one of four reactors at the Chernobyl nudear power plant in the Ukraine suffered a series of explosions and a meltdown - the worst nudear accident in history. Radioactive fallout contaminated more than 200,000 square kilometres of Europe, leading to the eventual relocation of more than 350,000 people.

So far, the report says, fewer than $\mathbf{5 0}$ deaths have been directly attributed to radiation exposure - most of them rescue workers who died of acute radiation syndrome shortly after the disaster. The authors estimate that the incidence of radiation-induced cancer rose by only about $3 \%$ in the affected areas.

They add that the thousands of children who contracted thyroid cancer after the accident are likely to have a $99 \%$ survival rate, higher than the $80-85 \%$ previously thought.

Poverty and mental-health problems, such as stress, depression and anxiety, pose a much greater threat to the local communities than radiation, the report concludes. It argues that future aid should focus on improving the healthcare system and promoting local economic development.

Valeska Stephan 